IJMMS 30:9 (2002) 515-520

PII. S0161171202111276

http://ijmms.hindawi.com

(c) Hindawi Publishing Corp.

\title{
ON NEW GENERALIZATIONS OF HARDY'S INTEGRAL INEQUALITIES
}

\section{LÜ ZHONGXUE and XIE HONGZHENG}

Received 1 November 2001

We give some new generalizations of Hardy's integral inequalities.

2000 Mathematics Subject Classification: 26D15.

1. Introduction. The classical Hardy inequality [3] states that: for $f(x) \geq 0, p>1$, $1 / p+1 / q=1$, and $0<\int_{0}^{\infty} f^{p}(x) d x<\infty$,

$$
\int_{0}^{\infty}\left[\frac{1}{x} \int_{0}^{x} f(t) d t\right]^{p} d x<q^{p} \int_{0}^{\infty} f^{p}(t) d t
$$

where $q=p /(p-1)$ is the best possible constant.

The dual form of (1.1) is as follows: if $0<\int_{0}^{\infty}(x f(x))^{p} d x<\infty$, then

$$
\int_{0}^{\infty}\left(\int_{x}^{\infty} f(t) d t\right)^{p} d x<p^{p} \int_{0}^{\infty}(t f(t))^{p} d t
$$

where the constant $p^{p}$ in (1.2) is still best possible.

Bicheng et al. [2] gave some new generalizations of (1.1) which can be stated as follows:

$$
\begin{aligned}
& \int_{a}^{b}\left(\frac{1}{x} \int_{a}^{x} f(t) d t\right)^{p} d x<q^{p}\left[1-\left(\frac{a}{b}\right)^{1 / q}\right]^{p} \int_{a}^{b} f^{p}(t) d t ; \\
& \int_{a}^{\infty}\left(\frac{1}{x} \int_{a}^{x} f(t) d t\right)^{p} d x<q^{p} \int_{a}^{\infty}\left[1-\theta_{p}(t)\right] f^{p}(t) d t \quad\left(0<\theta_{p}(t)<1\right) ; \\
& \int_{0}^{b}\left(\frac{1}{x} \int_{0}^{x} f(t) d t\right)^{p} d x<q^{p} \int_{0}^{b}\left[1-\left(\frac{t}{b}\right)^{1 / q}\right] f^{p}(t) d t,
\end{aligned}
$$

where $\theta_{p}(t)=(1 / p) \sum_{k=1}^{\infty}\left(\begin{array}{c}p \\ k+1\end{array}\right)(-1)^{k-1}(a / t)^{k / q}>0$ for $t>a>0$, and $\theta_{p}(a)=1 / q$.

Recently, Becheng and Debnath [1] gave improvement of (1.3) and some generalizations of (1.2):

$$
\begin{aligned}
& \int_{a}^{b}\left(\frac{1}{x} \int_{a}^{x} f(t) d t\right)^{p} d x<q^{p} \eta_{p}(a, b) \int_{a}^{b} f^{p}(t) d t \\
& \int_{a}^{\infty}\left(\int_{x}^{\infty} f(t) d t\right)^{p} d x<p^{p} \int_{a}^{\infty}\left[1-\left(\frac{a}{t}\right)^{1 / p}\right](t f(t))^{p} d t \\
& \int_{0}^{b}\left(\int_{x}^{b} f(t) d t\right)^{p} d x<p^{p} \int_{0}^{b} \mu_{p}(t)(t f(t))^{p} d t
\end{aligned}
$$


where the constants $\eta_{p}(a, b)=\max _{a \leq t \leq b}\left\{(1 / q) t^{1 / q} \int_{t}^{b} x^{-1-1 / q}\left[1-(a / x)^{1 / q}\right]^{p-1} d x\right\}$, $\mu_{p}(t)=(1 / p)\left\{1-(t / b)^{1 / p}\right\}^{p}(b / t)^{1 / p}$.

In this paper, we show some new improvements and generalizations of the inequalities (1.1) and (1.2).

\section{Main results}

LEMMA 2.1. Let $a \geq 0, p>1,1 / p+1 / q=1-1 / r, f \geq 0, r>1$, and $0<\int_{a}^{\infty} f^{p}(t) d t<$ $\infty$. Then, there exists a real number $x_{0} \in(a, \infty)$ such that, for any $x>x_{0}$, the following inequality is true:

$$
\begin{aligned}
\left(\int_{a}^{x} f(t) d t\right)^{p}< & \left(\frac{p q(p-1)}{(p+q)(p-1)-p}\right)^{p-1}\left(1-\frac{1}{r}\right)^{p-1} \\
& \times\left(x^{1-1 /(1-1 / r) q(p-1)}-a^{1-1 /(1-1 / r) q(p-1)}\right)^{p-1} \int_{a}^{x} t^{1 /(1-1 / r) q} f^{p}(t) d t
\end{aligned}
$$

Proof. By Hölder's inequality, we have

$$
\begin{aligned}
\left(\int_{a}^{x} f(t) d t\right)^{p} & =\left(\int_{a}^{x} t^{1 /(1-1 / r) p q} f(t) t^{-1 /(1-1 / r) p q} d t\right)^{p} \\
& \leq \int_{a}^{x} t^{1 /(1-1 / r) q} f^{p}(t) d t\left(\int_{a}^{x}\left(t^{-1 /(1-1 / r) p q}\right)^{p /(p-1)} d t\right)^{p-1} \\
& =\left(\frac{p q(p-1)}{(p+q)(p-1)-p}\right)^{p-1}\left(1-\frac{1}{r}\right)^{p-1} \\
& \times\left(x^{1-1 /(1-1 / r) q(p-1)}-a^{1-1 /(1-1 / r) q(p-1)}\right)^{p-1} \int_{a}^{x} t^{1 /(1-1 / r) q} f^{p}(t) d t
\end{aligned}
$$

We need to show that there exists a real number $x_{0} \in(a, \infty)$, such that (2.2) does not assume equality for any $x>x_{0}$. Otherwise, there exists $x=x_{n} \in(a, \infty)$, where $n=1,2,3, \ldots, x_{n} \uparrow \infty$, such that (2.2) becomes an equality. By the same argument, there exists a real number $c>0$, and an integer $N$, such that for $n>N$,

$$
\left(t^{1 /(1-1 / r) p q} f(t)\right)^{p}=c\left(t^{-1 /(1-1 / r) p q}\right)^{p /(p-1)} \text { a.e. in }\left[a, x_{n}\right]
$$

Hence

$$
\begin{aligned}
\int_{a}^{x_{n}} f^{p}(t) d t & =\int_{a}^{x_{n}} c \frac{t^{-1 /(1-1 / r) q(p-1)}}{t^{1 /(1-1 / r) q}} d t \\
& =\int_{a}^{x_{n}} c t^{-p /(1-1 / r) q(p-1)} d t \rightarrow \infty \quad \text { as } n \rightarrow \infty
\end{aligned}
$$

This is a contradiction to the fact that $0<\int_{a}^{\infty} f^{p}(t) d t<\infty$. Hence, (2.1) holds true and the proof is complete. 
LEMMA 2.2. Let $b>0, p>1,1 / p+1 / q=1-1 / r, f \geq 0, r>1$, and let $0<$ $\int_{0}^{b} t^{p-1+1 /(1-1 / r)} f^{p}(t) d t<\infty$. Then, there exists a real number $x_{0} \in(0, b)$ such that, for any $x \in\left(0, x_{0}\right)$, the following inequality is true:

$$
\begin{aligned}
\left(\int_{x}^{b} f(t) d t\right)^{p}< & \left(\left(1-\frac{1}{r}\right) p\right)^{p-1}\left(x^{-1 /(1-1 / r) p}-b^{-1 /(1-1 / r) p}\right)^{p-1} \\
& \times \int_{x}^{b} t^{p-1+(p-1) /(1-1 / r) p} f^{p}(t) d t
\end{aligned}
$$

Proof. For any $x \in(0, b)$, by Hölder's inequality, we have

$$
\begin{aligned}
\left(\int_{x}^{b} f(t) d t\right)^{p}= & {\left[\int_{x}^{b} t^{(1+(1-1 / r) p)(p-1) /(1-1 / r) p^{2}} f(t) t^{-(1+(1-1 / r) p)(p-1) /(1-1 / r) p^{2}} d t\right]^{p} } \\
\leq & \int_{x}^{b} t^{(1+(1-1 / r) p)(p-1) /(1-1 / r) p} f^{p}(t) d t\left(\int_{x}^{b} t^{-(1+(1-1 / r) p) /(1-1 / r) p} d t\right)^{p-1} \\
= & \left(\left(1-\frac{1}{r}\right) p\right)^{p-1}\left(x^{-1 /(1-1 / r) p}-b^{-1 /(1-1 / r) p}\right)^{p-1} \\
& \times \int_{x}^{b} t^{p-1+(p-1) /(1-1 / r) p} f^{p}(t) d t
\end{aligned}
$$

We need to show that there exists a real number $x_{0} \in(0, b)$, such that (2.6) does not assume equality for any $x \in\left(0, x_{0}\right)$. Otherwise, there exists $x=x_{n} \in(0, b)$, where $n=1,2,3, \ldots, x_{n} \downarrow 0$, such that (2.6) becomes an equality. Then there exist $c_{n}$ and $d_{n}$ which are not always zero, such that (see [4, page 29])

$$
\begin{aligned}
& c_{n}\left[t^{(1+(1-1 / r) p)(p-1) /(1-1 / r) p^{2}} f(t)\right]^{p} \\
& \quad=d_{n}\left[t^{-(1+(1-1 / r) p)(p-1) /(1-1 / r) p^{2}}\right]^{p /(p-1)} \text { a.e. in }\left[x_{n}, b\right] .
\end{aligned}
$$

Since $f(t) \neq 0$ a.e. in $(0, b)$, there exists an integer $N$ such that, for $n>N, f(t) \neq 0$ a.e. in $\left(0, x_{n}\right)$. Thus, for both $c_{n}=c \neq 0$ and $d_{n}=d \neq 0$ for $n>N$,

$$
\int_{0}^{b} t^{p-1+1 /(1-1 / r)} f^{p}(t) d t=\lim _{n \rightarrow \infty} \int_{x_{n}}^{b} \frac{t^{-(1+1 /(1-1 / r) p)}}{t^{1-(1+1 /(1-1 / r) p)}} d t=\frac{d}{c} \lim _{n \rightarrow \infty} \int_{x_{n}}^{b} \frac{d t}{t}=\infty .
$$

This contradicts the fact that $0<\int_{0}^{b} t^{p-1+1 /(1-1 / r)} f^{p}(t) d t<\infty$. Hence, (2.5) is valid and this completes the proof of the lemma.

LEMMA 2.3. Let $a>0, p>1,1 / p+1 / q=1-1 / r, f \geq 0, r>1$, and $0<$ $\int_{a}^{\infty} t^{p-1+1 /(1-1 / r)} f^{p}(t) d t<\infty$. Then, there exists a real number $x_{0} \in(a, \infty)$ such that, for any $x \in\left(a, x_{0}\right)$, the following inequality is true:

$$
\left(\int_{x}^{\infty} f(t) d t\right)^{p}<\left(\left(1-\frac{1}{r}\right) p\right)^{p-1} x^{-(p-1) /(1-1 / r) p} \int_{x}^{\infty} t^{p-1+(p-1) /(1-1 / r) p} f^{p}(t) d t .
$$


Proof. For any $x \in(a, \infty)$, by Hölder's inequality, we have

$$
\left(\int_{x}^{\infty} f(t) d t\right)^{p} \leq\left(\left(1-\frac{1}{r}\right) p\right)^{p-1} x^{-(p-1) /(1-1 / r) p} \int_{x}^{\infty} t^{p-1+(p-1) /(1-1 / r) p} f^{p}(t) d t .
$$

We show that there exists a real number $x_{0} \in(a, \infty)$, such that (2.10) does not assume equality for any $x \in\left(a, x_{0}\right)$. Otherwise, there exists $x=x_{n} \in(a, \infty)$, where $n=1,2,3, \ldots, x_{n} \downarrow a$, such that (2.10) becomes an equality. By the same argument there exist a real number $c>0$, and an integer $N$, such that for $n>N$,

$$
\begin{aligned}
& {\left[t^{(1+(1-1 / r) p)(p-1) /(1-1 / r) p^{2}} f(t)\right]^{p}} \\
& \quad=c\left[t^{-(1+(1-1 / r) p)(p-1) /(1-1 / r) p^{2}}\right]^{p /(p-1)} \text { a.e. in }\left[x_{n}, \infty\right)
\end{aligned}
$$

and hence $\int_{a}^{\infty} t^{p-1+1 /(1-1 / r)} f^{p}(t) d t=c \lim _{n \rightarrow \infty} \int_{x_{n}}^{\infty}(d t / t)=\infty$. This contradicts the fact that $0<\int_{a}^{\infty} t^{p-1+1 /(1-1 / r)} f^{p}(t) d t<\infty$. Hence (2.9) is valid and this completes the proof of the lemma.

THEOREM 2.4. Let $0<a<b, p>1,1 / p+1 / q=1-1 / r, f \geq 0, r>1$, and $0<$ $\int_{a}^{\infty} f^{p}(t) d t<\infty$. Then

$$
\int_{a}^{b}\left(\frac{1}{x} \int_{a}^{x} f(t) d t\right)^{p} d x<\left(\frac{p q(p-1)}{(p+q)(p-1)-p}\right)^{p}\left(1-\frac{1}{r}\right)^{p} \eta(a, b) \int_{a}^{b} f^{p}(t) d t,
$$

where the constant

$$
\begin{gathered}
\eta(a, b)=\max _{a \leq t \leq b}\left\{\frac{(p+q)(p-1)-p}{p q(p-1)(1-1 / r)} t^{1 /(1-1 / r) q}\right. \\
\left.\quad \times \int_{t}^{b} x^{-1-1 /(1-1 / r) q}\left[1-\left(\frac{a}{x}\right)^{1-1 /(1-1 / r) q(p-1)}\right]^{p-1} d x\right\} \\
\eta(a, b)<\frac{(p+q)(p-1)-p}{p(p-1)}\left[1-\left(\frac{a}{b}\right)^{1-1 /(1-1 / r) q(p-1)}\right]^{p}
\end{gathered}
$$

Proof. In view of the proof of Lemma 2.1, we obtain

$$
\begin{aligned}
\int_{a}^{b}( & \left.\frac{1}{x} \int_{a}^{x} f(t) d t\right)^{p} d x \\
< & \left(\frac{p q(p-1)}{(p+q)(p-1)-p}\right)^{p-1}\left(1-\frac{1}{r}\right)^{p-1} \\
& \times \int_{a}^{b}\left\{\int_{t}^{b} x^{-1-1 /(1-1 / r) q}\left[1-\left(\frac{a}{x}\right)^{1-1 /(1-1 / r) q(p-1)}\right]^{p-1} d x\right\} t^{1 /(1-1 / r) q} f^{p}(t) d t \\
= & \left(\frac{p q(p-1)}{(p+q)(p-1)-p}\right)^{p}\left(1-\frac{1}{r}\right)^{p} \int_{a}^{b} g(t) f^{p}(t) d t,
\end{aligned}
$$


where the weight function $g(t)$ is defined by

$$
\begin{aligned}
g(t):= & \frac{(p+q)(p-1)-p}{p q(p-1)(1-1 / r)} t^{1 /(1-1 / r) q} \\
& \times \int_{t}^{b} x^{-1-1 /(1-1 / r) q}\left[1-\left(\frac{a}{x}\right)^{1-1 /(1-1 / r) q(p-1)}\right]^{p-1} d x, \quad t \in[a, b] .
\end{aligned}
$$

Setting $\eta(a, b):=\max _{a \leq t \leq b} \mathcal{g}(t)$, since $g(t)$ is a nonconstant continuous function, then by (2.14) we have (2.12). Since $g(b)=0$, and for any $t \in[a, b)$,

$$
\begin{aligned}
g(t) & <\frac{(p+q)(p-1)-p}{p q(p-1)(1-1 / r)} t^{1 /(1-1 / r) q} \int_{t}^{b} x^{-1-1 /(1-1 / r) q}\left[1-\left(\frac{a}{b}\right)^{1-1 /(1-1 / r) q(p-1)}\right]^{p-1} d x \\
& =\frac{(p+q)(p-1)-p}{p q(p-1)}\left[1-\left(\frac{a}{b}\right)^{1-1 /(1-1 / r) q(p-1)}\right]^{p-1}\left[1-\left(\frac{t}{b}\right)^{1 /(1-1 / r) q}\right] \\
& \leq \frac{(p+q)(p-1)-p}{p q(p-1)}\left[1-\left(\frac{a}{b}\right)^{1-1 /(1-1 / r) q(p-1)}\right]^{p-1}\left[1-\left(\frac{a}{b}\right)^{1 /(1-1 / r) q}\right] \\
& <\frac{(p+q)(p-1)-p}{p q(p-1)}\left[1-\left(\frac{a}{b}\right)^{1-1 /(1-1 / r) q(p-1)}\right]^{p} .
\end{aligned}
$$

This completes the proof.

THEOREM 2.5. Let $a>0, p>1,1 / p+1 / q=1-1 / r, f \geq 0, r>1$, and $0<$ $\int_{a}^{\infty}(t f(t))^{p} d t<\infty, 0<\int_{a}^{\infty} t^{p-1+1 /(1+1 / r)} f^{p}(t) d t<\infty$. Then

$$
\int_{a}^{\infty}\left(\int_{x}^{\infty} f(t) d t\right)^{p} d x<\left(\left(1-\frac{1}{r}\right) p\right)^{p} \frac{r}{r-p} \int_{a}^{\infty}\left[1-\left(\frac{a}{t}\right)^{(r-p) /(r-1) p}\right](t f(t))^{p} d t
$$

Proof. Applying (2.9), we have

$$
\begin{aligned}
\int_{a}^{\infty} & \left(\int_{x}^{\infty} f(t) d t\right)^{p} d x \\
& <\left(\left(1-\frac{1}{r}\right) p\right)^{p-1} \int_{a}^{\infty} x^{-(p-1) /(1-1 / r) p} \int_{x}^{\infty} t^{p-1+*(p-1) /(1-1 / r) p} f^{p}(t) d t d x \\
& =\left(\left(1-\frac{1}{r}\right) p\right)^{p-1} \int_{a}^{\infty}\left(\int_{a}^{t} x^{-(p-1) /(1-1 / r) p} d x\right) t^{p-1+(p-1) /(1-1 / r) p} f^{p}(t) d t \\
& =\left(\left(1-\frac{1}{r}\right) p\right)^{p} \frac{r}{r-p} \int_{a}^{\infty}\left[1-\left(\frac{a}{t}\right)^{(r-p) /(r-1) p}\right](t f(t))^{p} d t
\end{aligned}
$$

Hence, (2.17) is valid. This completes the proof of the theorem.

THEOREM 2.6. Let $b>0, p>1,1 / p+1 / q=1-1 / r, f \geq 0, r>1$, and $0<$ $\int_{0}^{b}(t f(t))^{p} d t<\infty, 0<\int_{0}^{b} t^{p-1+1 /(1-1 / r)} f^{p}(t) d t<\infty$. Then

$$
\int_{0}^{b}\left(\int_{x}^{b} f(t) d t\right)^{p} d x<\left(\left(1-\frac{1}{r}\right) p\right)^{p} \int_{0}^{b} \mu(t)(t f(t))^{p} d t
$$


where $\mu(t):=1 /(1-1 / r) p\left\{\int_{0}^{t} x^{-(p-1) /(1-1 / r) p}\left[1-(x / b)^{1 /(1-1 / r) p}\right]^{p-1} d x\right\} t^{(p-r) /(r-1) p}$, $t \in(0, b]$.

Proof. Applying (2.5), we have

$$
\begin{aligned}
\int_{0}^{b}\left(\int_{x}^{b} f(t) d t\right)^{p} d x< & \left(\left(1-\frac{1}{r}\right) p\right)^{p-1} \int_{0}^{b}\left(x^{-1 /(1-1 / r) p}-b^{-1 /(1-1 / r) p}\right)^{p-1} \\
& \times \int_{x}^{b} t^{p-1+(p-1) /(1-1 / r) p} f^{p}(t) d t d x \\
= & \left(\left(1-\frac{1}{r}\right) p\right)^{p-1} \int_{0}^{b}\left(\int_{0}^{t} x^{-(p-1)(1-1 / r) p}\left[1-\left(\frac{x}{b}\right)^{1 /(1-1 / r) p}\right]^{p-1} d x\right) \\
& \times t^{(p-r) /(r-1) p}(t f(t))^{p} d t \\
= & \left(\left(1-\frac{1}{r}\right) p\right)^{p} \int_{0}^{b} \mu(t)(t f(t))^{p} d t
\end{aligned}
$$

where $\mu(t):=1 /(1-1 / r) p\left\{\int_{0}^{t} x^{-(p-1) /(1-1 / r) p}\left[1-(x / b)^{1 /(1-1 / r) p}\right]^{p-1} d x\right\} t^{(p-r) /(r-1) p}$, $t \in(0, b]$. This proves (2.19) and the proof of the theorem is complete.

REMARK 2.7. Let $r \rightarrow \infty$, (2.1) changes into [2, (2.3)]. Hence, (2.1) is a generalization of $[2,(2.3)]$.

REMARK 2.8. Let $r \rightarrow \infty$, (2.5) and (2.9) change into [1, (3.1) and (3.5)], respectively. Hence (2.5) and (2.9) is generalization of $[1,(3.1)$ and (3.5)], respectively.

REMARK 2.9. Let $r \rightarrow \infty$, (2.12), (2.17), and (2.19) change into [1, (3), (4), and (5)], respectively. Hence, (2.12), (2.17), and (2.19) is generalization of [1, (3), (4), and (5)], respectively.

\section{REFERENCES}

[1] Y. Bicheng and L. Debnath, Generalizations of Hardy's integral inequalities, Int. J. Math. Math. Sci. 22 (1999), no. 3, 535-542.

[2] Y. Bicheng, Z. Zhuohua, and L. Debnath, Note on new generalizations of Hardy's integral inequality, J. Math. Anal. Appl. 217 (1998), no. 2, 321-327.

[3] G. H. Hardy, J. E. Littlewood, and G. Pólya, Inequalities, 2nd ed., Cambridge University Press, London, 1952.

[4] J. A. Oguntuase and C. O. Imoru, New generalizations of Hardy's integral inequality, J. Math. Anal. Appl. 241 (2000), no. 1, 73-82.

LÜ ZhongXue: Department of BASic SCience of TeChNology College, XuZhou Normal UNIVERSITY, XUZHOU 221011, CHINA

E-mail address: 1vzx1@163. net

Xie Hongzheng: Department of Mathematics, Harbin Institute of Technology, HARBIN 150001, CHINA 


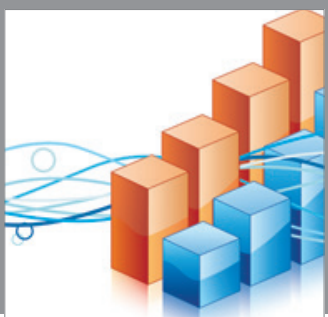

Advances in

Operations Research

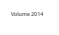

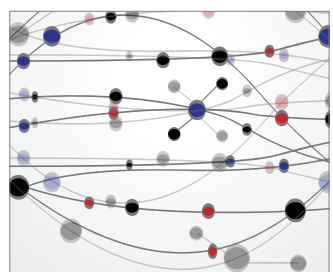

\section{The Scientific} World Journal
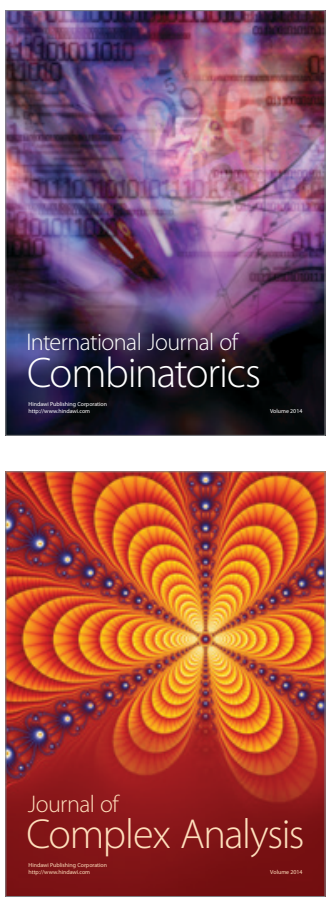

International Journal of

Mathematics and

Mathematical

Sciences
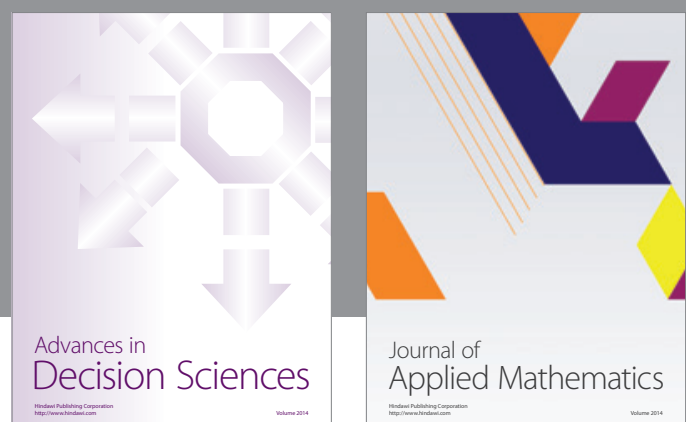

Journal of

Applied Mathematics
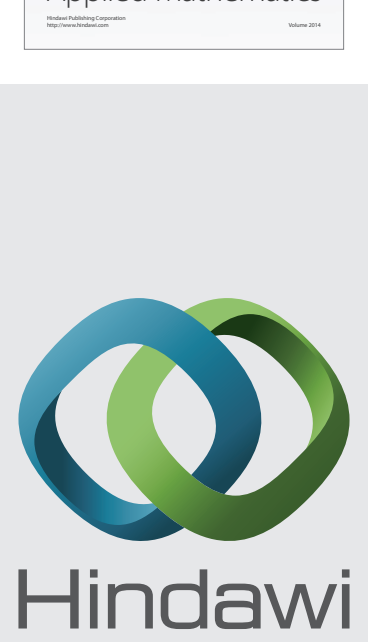

Submit your manuscripts at http://www.hindawi.com
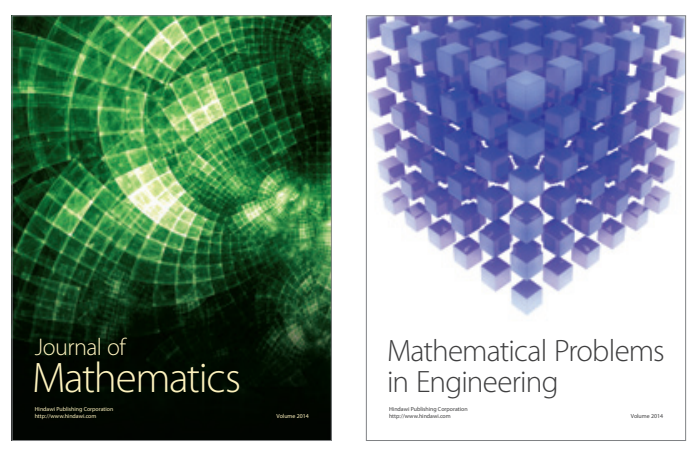

Mathematical Problems in Engineering
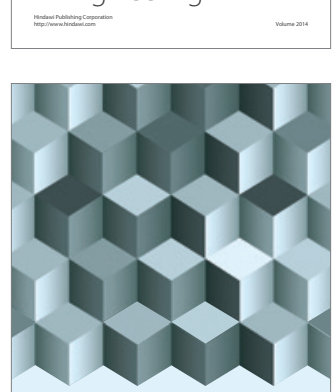

Journal of

Function Spaces
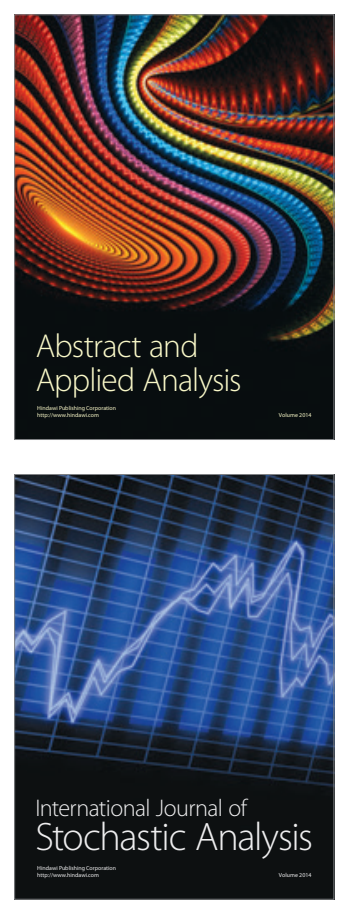

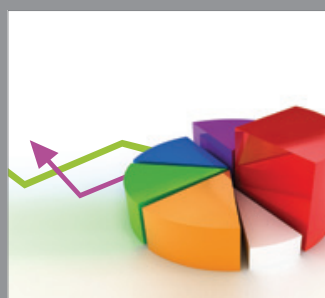

ournal of

Probability and Statistics

Promensencen
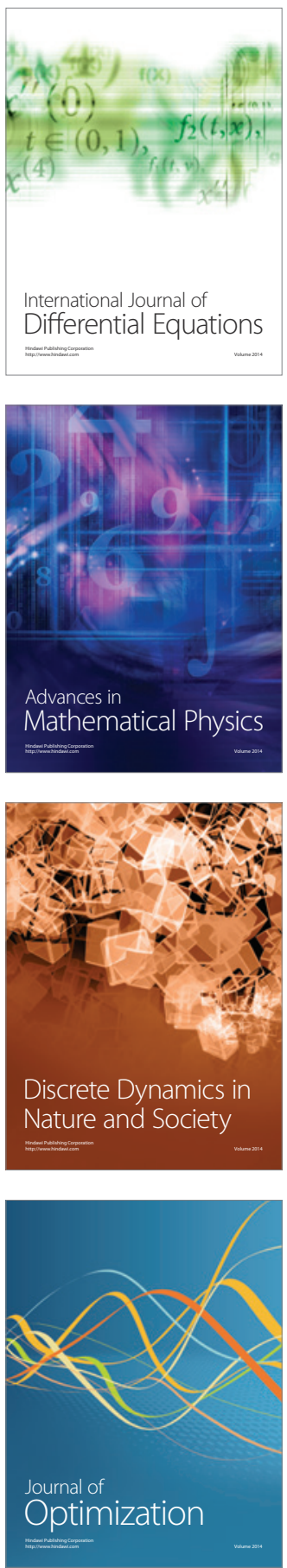